\title{
Defect Localisation in Photovoltaic Panels with the Help of Synchronized Thermography
}

\author{
Christian Schuss* $^{*}$, Kari Remes ${ }^{\dagger}$, Kimmo Leppänen ${ }^{\ddagger}$, Juha Saarela ${ }^{\dagger}$, Tapio Fabritius ${ }^{\dagger}$, \\ Bernd Eichberger ${ }^{\S}$, and Timo Rahkonen* \\ ${ }^{*}$ Circuits and Systems (CAS), University of Oulu, Finland; email: christian.schuss, timo.rahkonen@ee.oulu.fi \\ †Optoelectronics and Measurement Techniques Laboratory, University of Oulu, Finland; \\ email: kari.remes, juha.saarela, tapio.fabritius@ee.oulu.fi \\ ${ }_{\ddagger}^{\ddagger}$ Oy G.W. Berg \& Co Ab, Finland; email: kimmo.leppanen@gwb.fi \\ §Institute of Electronic Sensor Systems, Graz University of Technology, Austria; email: bernd.eichberger@tugraz.at
}

\begin{abstract}
This paper investigates defects in photovoltaic (PV) panels, more precisely, the location of defects in PV panels. With the help of electrical verification, it is possible to verify the impact of defects on output performances. However, it is not possible to determine the location of defects in order to address problems, for example in the manufacturing process of PV panels. In this paper, the focus lies on finding similarities in the location of defect areas in PV panels. Samples were characterised with the help of synchronized thermography (ST) in order to obtain infrared (IR) images of PV panels. IR-images are helpful to get a visual image on the health of PV panels and identify the position of defects. This information can be useful, for example to improve the fabrication process of $\mathrm{PV}$ panels.
\end{abstract}

Index Terms-defect, interconnection, photovoltaic cell, photovoltaic panel, solar energy, synchronized thermography.

\section{INTRODUCTION}

Commonly, photovoltaic (PV) panels are verified by electrical measurements in order to obtain the characteristic I-V (Current-Voltage) curve [1]-[3]. The slope of the I-V curve provides information on the output performance of the PV panel in terms of available output current and power at different operating voltages [4], [5]. Moreover, with the help of electrical measurements, parameters can be verified which are needed for PV simulation models [1]-[3], [6].

Photovoltaics are characterised at standard test conditions (STC). STC are given at an air mass (AM) 1.5, a solar radiation level $(\lambda)$ of $1000 \mathrm{~W} / \mathrm{m}^{2}$ and a PV cell temperature $\left(T_{c}\right)$ of 25 ${ }^{\circ} \mathrm{C}$. Under outdoor environmental conditions, it is difficult to maintain this kind of ambient conditions precisely. Therefore, outdoors, additional equipment such as a pyranometer is required during the electrical verification of $\mathrm{PV}$ panels for recording the current environmental conditions [1]-[3].

In previous research, we noticed variations in output power of PV panels which exceeded the specifications of tolerance limits of PV manufacturers [3]. Some PV panels produced significantly less power than other PV panels while it was not possible to clearly determine the origin of the observed variations in output power [3]. In the PV panels, there were no signs of weak connections or breakages in PV cells which could help to explain the differences in output power levels.

A major disadvantage of the electrical verification of PV panels is that a precise illumination and temperature are required in order to obtain comparable measurement results. Moreover, electrical measurements do not provide information on the location of defects in PV panels. Thus, we characterised PV panels with the help of synchronized thermography (ST) to obtain a better understanding of the cause for the variations in output power.

In this paper, we have used an infrared (IR) camera which offered a higher resolution than the IR-camera used in previous research [7]. In this way, the opportunity is given to localise defects in PV panels more precisely. In addition, we use a portable IR-camera which can be attached to a smartphone, for example an iPhone. As a result, ST can be become a portable measurement tool and can be useful for consumers to analyse their PV panels.

\section{BACKGROUND AND RELATED WORK}

\section{A. Behaviour of Photovoltaics}

In PV simulation models, each $\mathrm{PV}$ cell in a panel is considered to be equal to the others. Commonly, PV panels are made out of a large series connection of PV cells. If one of the PV cells in the panel is defect, the PV panel performance can be significantly decreased. In a series connection of PV cells, the short-circuit current $\left(I_{s c}\right)$ depends on the short-circuit current of the weakest PV cell of the interconnection $\left(I_{s c, \min }\right)$ [7]-[9], as obtained by the following equation:

$$
P_{\text {ideal }}=V_{o c} \times I_{s c, \text { min }} \quad \text { whereas } \quad I_{s c, \text { min }}<I_{s c}
$$

where $P_{\text {ideal }}$ is the ideal power of the PV panel and $V_{o c}$ is the open-circuit voltage of the PV panel.

\section{B. Configuration of a PV panel}

Fig. 1 shows the interconnection of PV cells in a PV panel. The example is taken from a PV panel which contains $36 \mathrm{PV}$ cells and produces an output power of 80 watts. As seen in Fig. 1, all PV cells are connected in series with each other. In each row, there are 9 PV cells. Each string of PV cells is then connected to the next string of PV cells in the next row. The corner points are connected to a voltage terminal on which the output power can be obtained. 


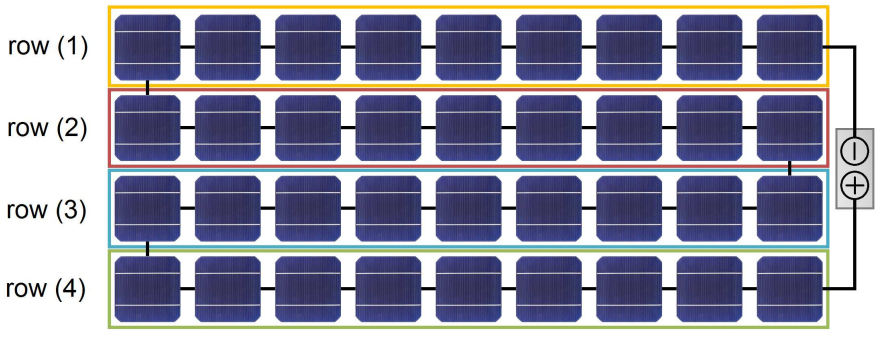

Fig. 1: Connection of PV cells in a PV panel

\section{Background of Synchronized Thermography}

Leppänen et al. developed synchronized thermography (ST) for the characterisation of thin films [10]-[12]. The method involved electrical heating of the conductive layer to measure its non-uniformity. At present, the closest technique comparable to ST is lock-in thermography (LIT). LIT has been applied to study defects of PV cells which are not encapsulated [13]-[17]. However, if PV cells are encapsulated by glass, it is difficult to measure them with the help of LIT, because temperature differences due to the modulated heating are too small and are smoothed by glass.

In previous research, we demonstrated that ST can be used to characterise crystalline PV cells and panels on top of the conductive layer and through glass [8]. The basic measurement setup of ST is shown in Fig. 2. Here, an external power supply of $12 \mathrm{~V}$ was applied to heat up the PV panels for $45 \mathrm{sec}$ in a dark, non-illuminated environment $\left(\lambda=0 \mathrm{~W} / \mathrm{m}^{2}\right)$, as in previous research [7], [8]. This ambient circumstances are comparable to dark lock-in thermography (DLIT) [14]. After $45 \mathrm{sec}$, IR-images were taken with the help of a Optris PI 640 IR-camera (image resolution: 640x480) and a Flir ONE iOS IR-camera (camera resolution: 160x120, image resolution: 640x480). In previous research, we used a Flir b60 IR-camera (image resolution: 180x180) [7], [8].

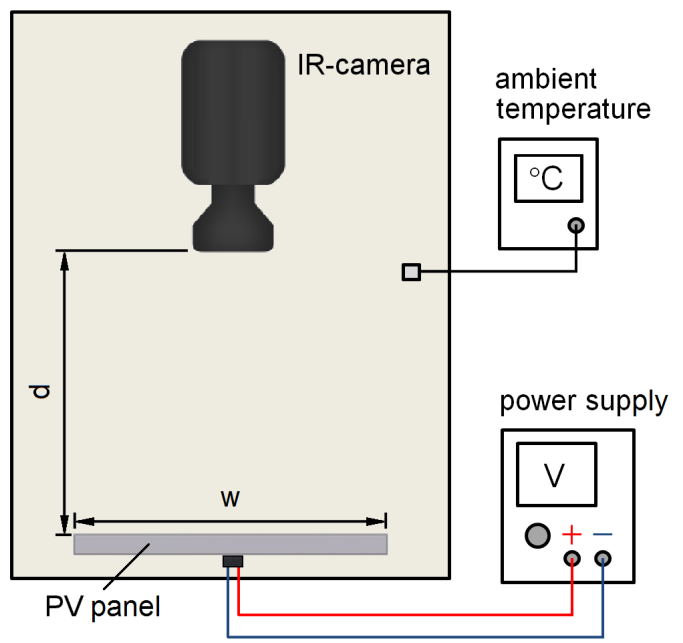

Fig. 2: Synchronized thermography measurement setup

\section{Stage for Investigating PV panels}

The focus of this research is to find defects in PV panels before these PV panels are installed in the field. In this way, mismatches between the available output powers of PV panels can be avoided. In this stage, the IR-images are taken in a dark environment $\left(\lambda=0 \mathrm{~W} / \mathrm{m}^{2}\right)$ when PV panels are not illuminated, for example by the sun. Other research focuses on the evaluation of PV panels which are already installed in the field in order to investigate the performance of PV plants [18]-[20].

PV panels which are installed in the field can suffer from different failures such as encapsulation failures, module corrosion, broken interconnection and solder buses failures, cells cracking, and dust [18]. Cells cracking described in [18] which can develop in different stages of the lifetime of a PV panel is similar to hairline cracks which were found in our research [7]-[9]. In both cases, a part of the PV cell becomes electrically disconnected from the rest of the PV cell.

\section{SyNCHRONIZED THERMORGRAPHY OF PV PANELS}

\section{A. Measurement Setup and Measurement Sample}

The main difference between the IR-camera in this paper and the IR-camera used in previous research lies in the resolution of the IR-image. With the help of the higher resolution of IR-images, we expect to locate defects in the PV panels more precisely. Similarly, the resolution of a portable IR-camera is important which can be attached to portable devices such as smartphones. This type of portable IR-cameras can also lower the costs of the measurement setup. The alignment of the measurement setup (see Fig. 2) was done in such a way that the IR-image covers the complete PV panel. Thus, the distance of the camera $(d)$ was adjusted to the width of the PV panel $(w)$. In this way, the use of the resolution of the IR-camera could be optimised.

The type of PV panel used in this research is the same as in previous research [3], [7], [8]. Fig. 3 shows the PV panel, to be more exact the model DSP-5P from the manufacturer [lux.pro] Corporation. The PV manufacturer provides tolerance limits of $\pm 3 \%$ for their PV panels on output performances at standard test conditions (STC) $\left(\lambda=1000 \mathrm{~W} / \mathrm{m}^{2}\right.$ and $\left.T_{c}=25{ }^{\circ} \mathrm{C}\right)$. As seen in Fig. 3, the PV panel is made out of 18 polycrystalline PV cells which are connected in series with each other. Table I presents the available data from the PV manufacturer.

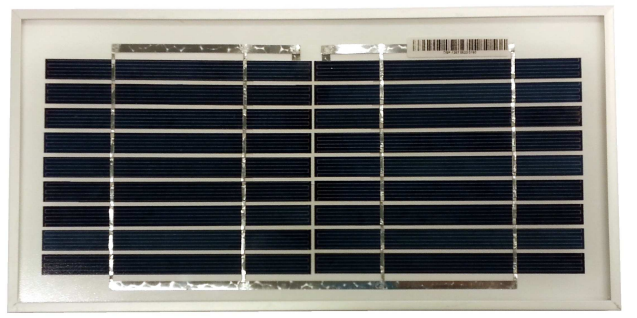

Fig. 3: PV panel DSP-5P from [lux.pro] Corporation 
TABLE I: Available data of the [lux.pro] DSP-5P

\begin{tabular}{|c|c|}
\hline Parameter & Value \\
\hline $\mathrm{P}_{\text {mpp }}[\mathrm{W}]$ & 5.00 \\
\hline $\mathrm{V}_{\mathrm{oc}}[\mathrm{V}]$ & 11.25 \\
\hline $\mathrm{I}_{\mathrm{sc}}[\mathrm{A}]$ & 0.81 \\
\hline $\mathrm{V}_{\mathrm{mpp}}[\mathrm{V}]$ & 9.00 \\
\hline $\mathrm{I}_{\mathrm{mpp}}[\mathrm{A}]$ & 0.56 \\
\hline
\end{tabular}

AM1.5; $\lambda=1000 \mathrm{~W} / \mathrm{m}^{2} ; T_{c}=25^{\circ} \mathrm{C} ;$ standard test conditions (STC)

\section{B. Obtaining and Analysing IR-images}

We decided to use the same parameters as in previous research for forward-biasing the encapsulated PV panels in order to obtain comparable results. Thus, we heated the PV panels for 45 seconds [3], [7], [8]. At the same time with IR-imaging, the temperature was measured from a reference sample which was not heated. In addition, the ambient temperature was measured for reference. In this way, the scaled IR-images show temperature variations above the ambient temperature.

We measured six PV panels with both, the Optris PI 640 IR-camera and the Flir ONE iOS IR-camera and, then, calculated the temperature map of all samples afterwards. The temperature scale bar was formatted according to the obtained temperature rises. Tables II and III present the maximum temperature variation in the particular PV panel obtained with the different IR-cameras. Due to a maximum temperature of $3.6{ }^{\circ} \mathrm{C}$ for both cameras, we decided to format the temperature scale from 0 to $4{ }^{\circ} \mathrm{C}$ above the ambient temperature.

TABLE II: Maximum temperature in PV panels obtained with the Optris PI 640 IR-camera

\begin{tabular}{|l|l|}
\hline PV panel 1 & $3.5^{\circ} \mathrm{C}$ \\
\hline PV panel 2 & $3.4{ }^{\circ} \mathrm{C}$ \\
\hline PV panel 3 & $3.0^{\circ} \mathrm{C}$ \\
\hline PV panel 4 & $3.0^{\circ} \mathrm{C}$ \\
\hline PV panel 5 & $3.6^{\circ} \mathrm{C}$ \\
\hline PV panel 6 & $3.5{ }^{\circ} \mathrm{C}$ \\
\hline
\end{tabular}

TABLE III: Maximum temperature in PV panels obtained with the Flir ONE iOS IR-camera

\begin{tabular}{|l|l|}
\hline PV panel 1 & $3.1{ }^{\circ} \mathrm{C}$ \\
\hline PV panel 2 & $3.2^{\circ} \mathrm{C}$ \\
\hline PV panel 3 & $3.1{ }^{\circ} \mathrm{C}$ \\
\hline PV panel 4 & $2.9^{\circ} \mathrm{C}$ \\
\hline PV panel 5 & $3.6^{\circ} \mathrm{C}$ \\
\hline PV panel 6 & $3.1{ }^{\circ} \mathrm{C}$ \\
\hline
\end{tabular}

Figures from 4 to 9 illustrate the temperature distribution of the PV panels 1 to 6 . For comparison, the IR-images obtained with the Flir b60 IR-camera are also shown [7], [8]. In addition, the shapes of the PV cells and connecting wires are also illustrated in order to show approximately the position of the cells and wires in the IR-image. In previous research, we obtained the highest power in the maximum power point (MPP) $\left(\mathrm{P}_{\mathrm{mpp}}\right)$ from PV panel 3, while the lowest power in the MPP was observed from PV panel 2 [3], [7], [8]. Table IV summarises the results of the electrical verification of the PV panels in terms of loss in power in the MPP $\left(\Delta \mathrm{P}_{\mathrm{mpp}}\right)$.

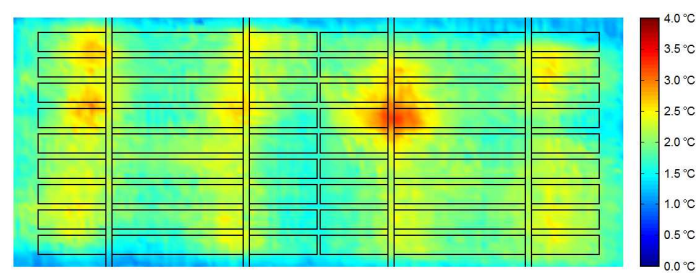

(a)

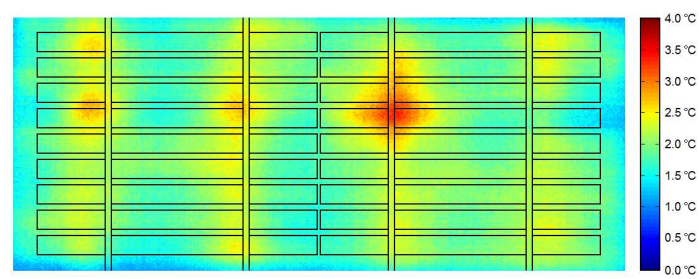

(b)

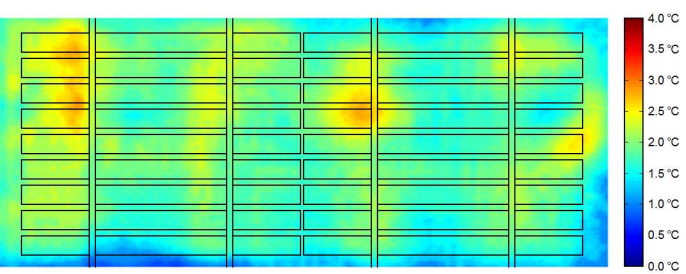

(c)

Fig. 4: Panel 1; (a) Flir b60 (b) Optris PI 640 (c) Flir ONE

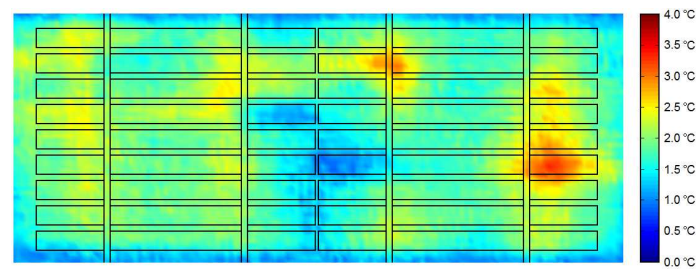

(a)

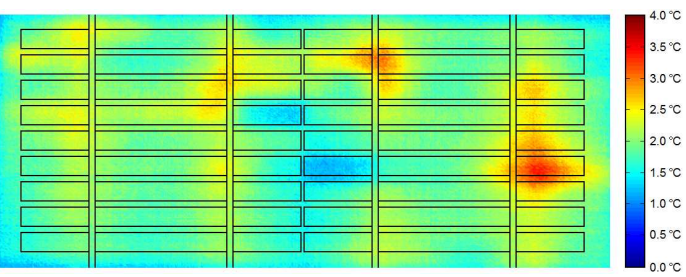

(b)

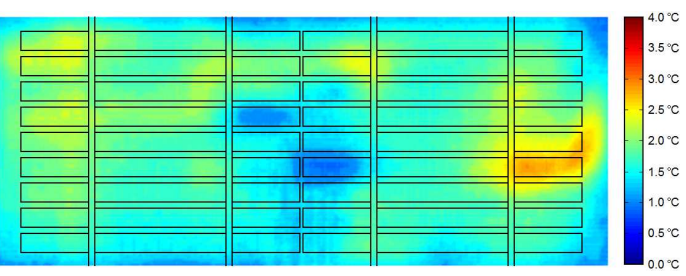

(c)

Fig. 5: Panel 2; (a) Flir b60 (b) Optris PI 640 (c) Flir ONE 


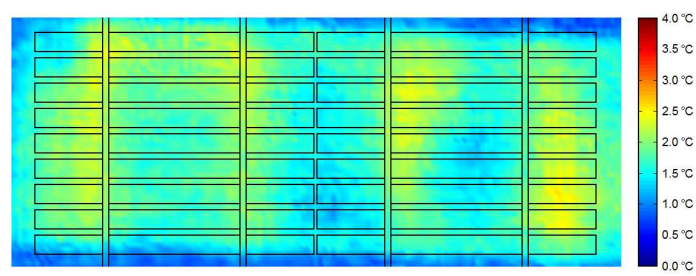

(a)

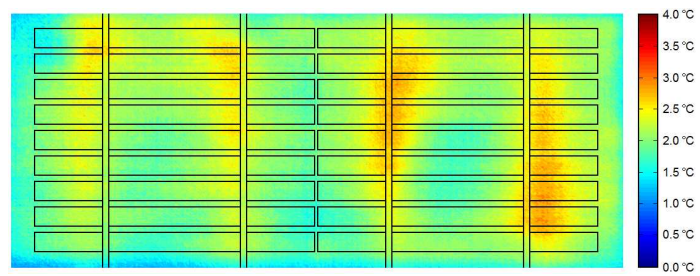

(b)

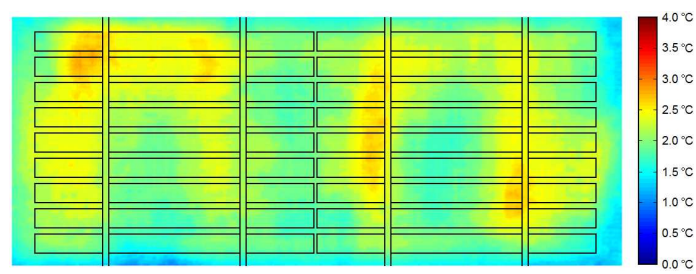

(c)

Fig. 6: Panel 3; (a) Flir b60 (b) Optris PI 640 (c) Flir ONE

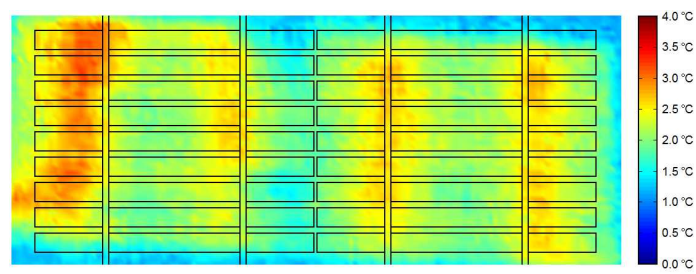

(a)

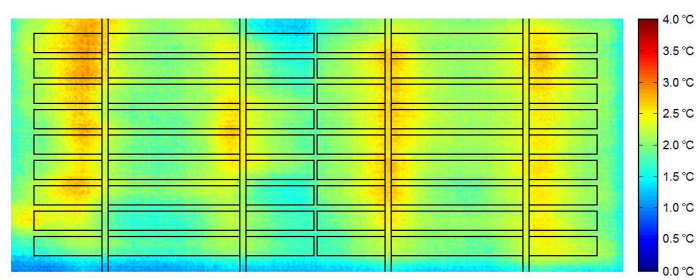

(b)

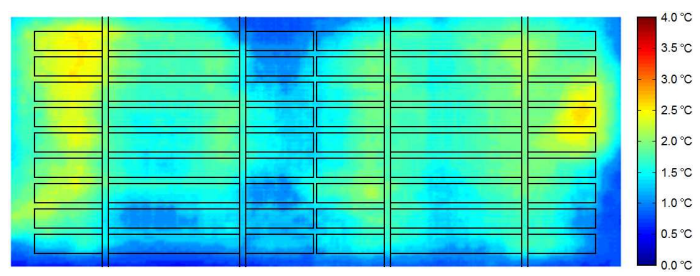

(c)

Fig. 7: Panel 4; (a) Flir b60 (b) Optris PI 640 (c) Flir ONE

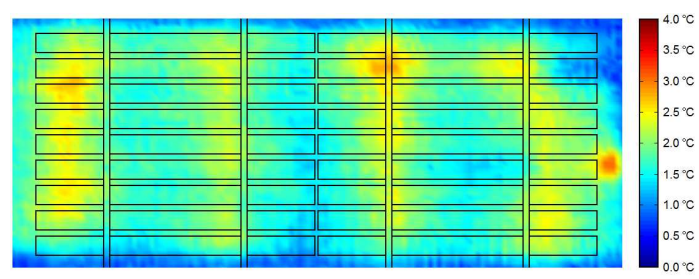

(a)

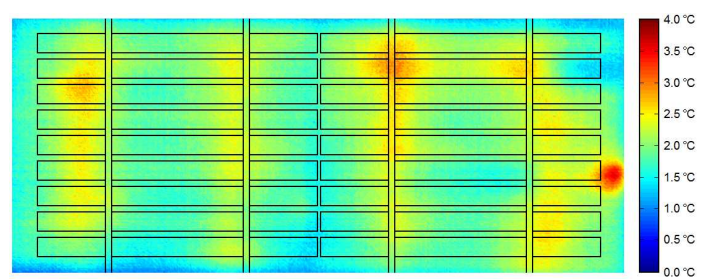

(b)

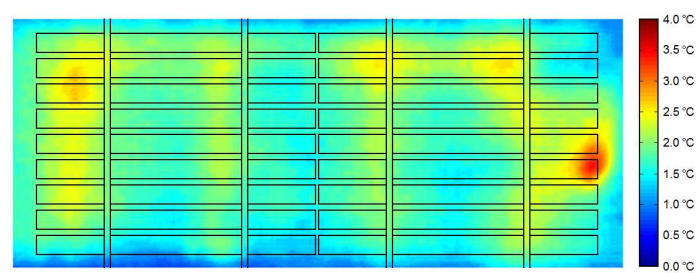

(c)

Fig. 8: Panel 5; (a) Flir b60 (b) Optris PI 640 (c) Flir ONE

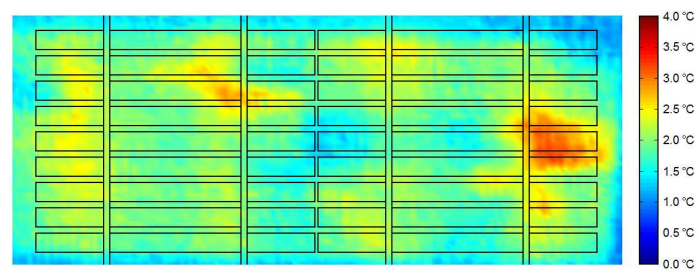

(a)

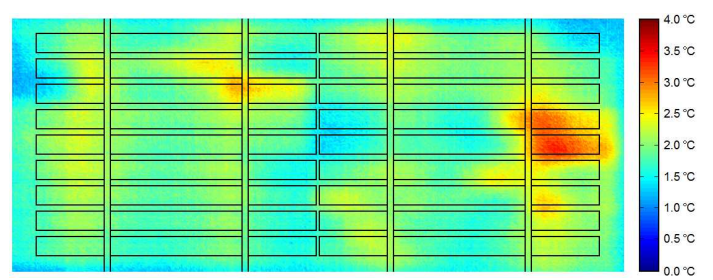

(b)

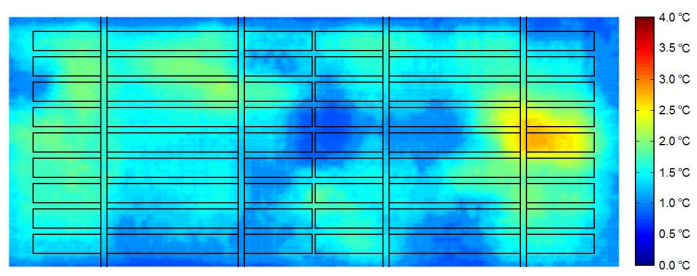

(c)

Fig. 9: Panel 6; (a) Flir b60 (b) Optris PI 640 (c) Flir ONE 
TABLE IV: Experimental verification of PV panels from [lux.pro] Corporation

\begin{tabular}{|c|c|c|}
\hline PV panel 1 & $\mathrm{P}_{\mathrm{mpp}}=1.933 \mathrm{~W}$ & $\Delta \mathrm{P}_{\mathrm{mpp}}=-16.72 \%$ \\
\hline PV panel 2 & $\mathrm{P}_{\mathrm{mpp}}=1.738 \mathrm{~W}$ & $\Delta \mathrm{P}_{\mathrm{mpp}}=-25.12 \%$ \\
\hline PV panel 3 & $\mathrm{P}_{\mathrm{mpp}}=2.321 \mathrm{~W}$ & $\Delta \mathrm{P}_{\mathrm{mpp}}= \pm 0.00 \%$ \\
\hline PV panel 4 & $\mathrm{P}_{\mathrm{mpp}}=2.135 \mathrm{~W}$ & $\Delta \mathrm{P}_{\mathrm{mpp}}=-8.01 \%$ \\
\hline PV panel 5 & $\mathrm{P}_{\mathrm{mpp}}=2.056 \mathrm{~W}$ & $\Delta \mathrm{P}_{\mathrm{mpp}}=-11.42 \%$ \\
\hline PV panel 6 & $\mathrm{P}_{\mathrm{mpp}}=1.776 \mathrm{~W}$ & $\Delta \mathrm{P}_{\mathrm{mpp}}=-23.48 \%$ \\
\hline
\end{tabular}

AM1.5; $\lambda=500 \mathrm{~W} / \mathrm{m}^{2} ; T_{c}=25^{\circ} \mathrm{C}$

standard test conditions (STC)

$\mathrm{PV}$ panel 3 used as reference for comparison

In experiments, the performance of PV panels 3 and 4 was similar, likewise the performance of PV panels 1 and 5 was similar. The output power of PV panel 2 and 6 was also similar, but significantly lower in comparison to the other panels. When comparing Figs. 4 to 9 with each other, we cannot see any significant temperature differences in the form of hot and cold spots in PV panels 3 and 4. The highest temperature elevation is obtained along the connecting wires. These connecting wires can be localised from the Fig. 3. However, for panel 1, 2, 5, and 6, clear hot and cold spots can be observed on the right-hand side of the PV panel.

In the cases PV cells have defects, the defect area can be physically and electrically disconnected from the rest of the PV cell, for example due to the presence of a hairline crack [8]. Thus, no current goes through the defect area and it does not heat up when the PV panel is forward biased. Actually, the current goes through the remaining area marking it warmer than a healthy PV cell in the panel. As a result, we are able to indicate defects in PV panels based on hot and cold spots. However, the actual damage in the PV cell is the cold spot in the temperature map. The location of the defect can be seen clearly in Figs. 4, 5, 8, and 9.

The 18 PV cells inside the PV panel from [lux.pro] Corporation are placed in two rows. One string of $9 \mathrm{PV}$ cells on the left-hand side with the remaining 9 PV cells on the rightside in the same layout. We can see hot and cold spots on the right-hand side of the particular PV panel. We can summarise that if defects are present, they are located in the middle of the string of PV cells on the right-hand side. We can summarise that if defects are present, they are located in the middle of the string of PV cells on the right-hand side. Fig. 10 illustrates the area of defects.

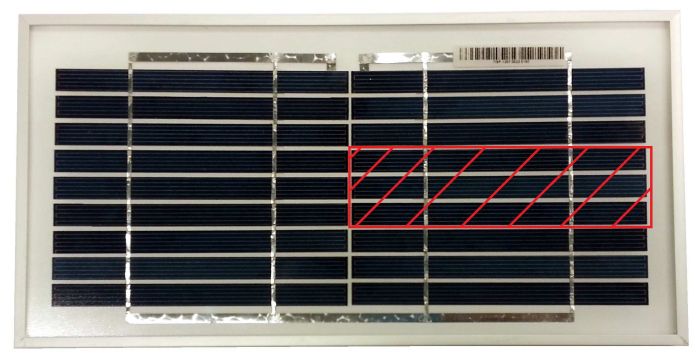

Fig. 10: Location of defects in the PV samples

\section{Estimating the Loss in Output Performance}

The resolution of the IR-image can have an impact on the estimation of the loss in output performance. The temperature map was evaluated in a similar way as in [9]. In this paper, the focus lies on the performance of the weakest PV cell of the interconnection. The loss in output power in the $\operatorname{MPP}\left(\Delta \mathrm{P}_{\mathrm{mpp}}\right)$ of the PV panel is estimated based on the estimated defect area of the perceived weakest PV cell of the PV panel, as described in Equation (1). In previous research, the temperature map of the whole PV panel from [lux.pro] Corporation was analysed [7].

The average temperature ( $\left.T_{\text {average }}\right)$ was calculated at each horizontal segment of the weakest PV cell of the panel. For each time, the difference in the average temperature was lower (i.e. focus on cold spots) than the threshold temperature $T_{\text {threshold }}$, the line segment was assumed to be defect. $T_{\text {threshold }}$ was taken from a healthy PV cell in the same string of PV cells in the same PV panel (outside the verified location of defects). The total amount of defect segments was converted as a percentage of the total line segments for comparison.

Fig. 11 shows a comparison of the obtained results. The focus lies on the PV panels of the sample in which significant cold and hot spots are located. In Fig. 11, the measured loss in output power, shown in Table IV, is compared with the estimated defect area based on the IR-images obtained with the help of synchronized thermography. Here, the difference in the estimated defect area is shown between the IR-images obtained with three different IR-cameras, the Flir b60, the Optrics PI 640 and the Flir ONE iOS IR-camera, respectively. It can be seen that the estimated defect area with synchronized thermography correlates with the measured loss in output power.

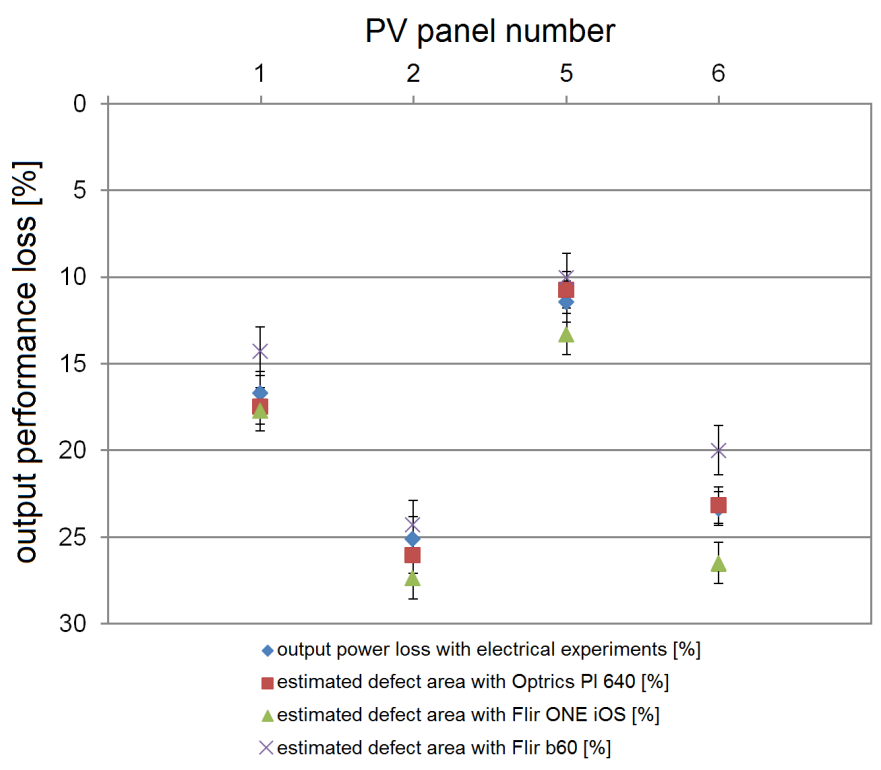

Fig. 11: Comparison of results 


\section{DISCUSSION AND CONCLUSION}

In this paper, we evaluated the temperature map with higher resolution IR-imaging in order to obtain more precise information about the location of defects in PV panels. Six PV panels with 18 cells each were investigated. Two PV panels were observed to be in healthy condition, but the other four PV samples were found to have defects. When comparing the temperature maps of the PV panels with defects, it was possible to locate the position of defects. In this research, we used the Optrics PI 640 IR-camera (image resolution: 640x480) which offered a higher resolution than the Flir b60 IR-camera (image resolution: 180x180) used in previous research.

Similarly, the resolution of the Flir ONE iOS IR-camera (camera resolution: 160x120, image resolution: 640x480) was suitably high enough to locate potential defects in the same PV panels based on the observed temperature variations in the IRimages. In previous research, IR-images were more pixelated and these circumstances had an impact on the estimation of losses in output performances such as the available power in the MPP $\left(\mathrm{P}_{\mathrm{mpp}}\right)$. The location of defects was observed to be in the same area with all IR-cameras, indicating potential problems, for example in the manufacturing or packaging process.

We demonstrated that the measured output power of PV panels correlates with the estimation of the defect area based on temperature variations in IR-images. IR-cameras with a superior resolution are capable of providing better estimations on the loss in performance. Generally speaking, synchronized thermography can be used for analysing and estimating the output performance of PV panels. The output power can be estimated based on the temperature differences in the weakest PV cell of the interconnection. The estimations correlated with the measured loss in output power in experiments.

\section{ACKNOWLEDGMENT}

We wish to thank Infotech Oulu and the Faculty of Information Technology and Electrical Engineering of the University of Oulu for financially supporting this research.

\section{REFERENCES}

[1] M.G. Villalva, J.R. Gazoli, and E.R. Filho, "Comprehensive Approach to Modeling and Simulation of Photovoltaic Arrays", IEEE Transactions on Power Electronics, vol. 24, No. 5, 2009, pp. 1198-1208.

[2] L. Cristaldi, M. Faifer, M. Rossi, and F. Ponci, "A Simple Photovoltaic Panel Model: Characterization Procedure and Evaluation of the Role of Environmental Measurements", IEEE Transactions on Instrumentation and Measurement, vol. 61, No: 10, 2012, pp. 2632-2641.

[3] C. Schuss, B. Eichberger, and T. Rahkonen, "Measurement and Verification of Photovoltaic (PV) Simulation Models", Proceedings of the IEEE International Instrumentation and Measurement Technology Conference (I2MTC), 2013, pp. 188-193.
[4] R.N. Hall, "Silicon Photovoltaic Cells", Solid State Electronics, vol. 24 No: 7, 1981, pp. 595-616.

[5] M.A. Green, "General solar cell curve factors including the effects of ideality factor, temperature and series resistance", Solid State Electronics, vol. 20, No: 3, 1977, pp. 265-266.

[6] W. De Soto, S.A. Klein, and W.A. Beckman, "Improvement and validation of a model for photovoltaic array performance", Solar Energy, vol. 80, No: 1, 2006, pp. 78-88.

[7] C. Schuss, K. Leppänen, Juha Saarela, Tapio Fabritius, B. Eichberger, and T. Rahkonen, "Detecting Defects in Photovoltaic Modules with the Help of Experimental Verification and Synchronized Thermography", Proceedings of the IEEE International Instrumentation and Measurement Technology Conference (I2MTC), 2015, pp. 97-102.

[8] C. Schuss, K. Remes, K. Leppänen, Juha Saarela, Tapio Fabritius, B. Eichberger, and T. Rahkonen, "Detecting Defects in Photovoltaic Cells and Panels and Evaluating the Impact on Output Performances", IEEE Transactions on Instrumentation and Measurement, vol. 65, issue: 5, 2016, pp. 1-12.

[9] C. Schuss, K. Remes, K. Leppänen, Juha Saarela, Tapio Fabritius, B. Eichberger, and T. Rahkonen, "Estimating the Impact of Defects in Photovoltaic Cells and Panels", Proceedings of the IEEE International Instrumentation and Measurement Technology Conference (I2MTC), 2016, pp. 121-126.

[10] K. Leppänen, J. Saarela, and T. Fabritius, "IR-imaging based system for detecting the defects of conductive materials", SPIE Optical Engineering+ Applications, 2014, pp. 92050M-92050M.

[11] K. Leppänen, J. Saarela, R. Myllylä, and T. Fabritius, "Electrical heating synchronized with IR imaging to determine thin film defects", Optics Express, vol. 21, No: 26, 2013, pp. 32358-32370.

[12] K. Leppänen, J. Saarela, and T. Fabritius, "Synchronized thermography for multi-layer thin film characterization", SPIE Optical Engineering+ Applications, 2014, pp. 917705-917705.

[13] O. Breitenstein, "Nondestructive local analysis of current-voltage characteristics of solar cells by lock-in thermography", Solar Energy Materials and Solar Cells, vol. 95, No: 10, 2011, pp. 2933-2936.

[14] O. Breitenstein, "Local efficiency analysis of solar cells based on lock-in thermography", Solar Energy Materials and Solar Cells, vol. 107, 2012, pp. 381-389.

[15] K. Ramspeck, K. Bothe, D. Hinken, B. Fischer, J. Schmidt, and R. Brendel, "Recombination current and series resistance imaging of solar cells by combined luminescence and lock-in thermography", Applied Physics Letters, vol. 90, No: 15, 2007, pp. 153502.

[16] I. Geisemeyer, F. Fertig, W. Warta, S. Rein, and M.C. Schubert, "Prediction of silicon PV module temperature for hot spots and worst case partial shading situations using spatially resolved lock-in thermography", Solar Energy Materials and Solar Cells, vol. 120, 2014, pp. 259-269.

[17] T.-Y. Chung, C.-H. Wang, K.-J. Chang, S.-Y. Chen, H.-H. Hsieh, C.-P. Huang, and C.-H. A Cheng, "Evaluation of the spatial distribution of series and shunt resistance of a solar cell using dark lock-in thermography", Applied Physics Letters, vol. 115, No: 3, 2014, pp. 034901.

[18] L. Cristaldi, M. Faifer, M. Lazzaroni, M.M.A.F. Khalil, M. Catelani, and L. Ciani, "Diagnostic architecture: A procedure based on the analysis of the failure causes applied to photovoltaic plants", Measurement, vol. 67, 2015, pp. 99-107.

[19] L. Cristaldi, M. Faifer, M. Rossi, S. Toscani, M. Catelani, L. Ciani, and M. Lazzaroni, "Simplified method for evaluating the effects of dust and aging on photovoltaic panels", Measurement, vol. 54, 2014, pp. 207-214.

[20] D. Galar, A. Thaduri, M. Catelani, and L. Ciani, "Context awareness for maintenance decision making: A diagnosis and prognosis approach", Measurement, 67, 2015, pp. 137-150. 